\title{
Predicting presence and abundance of demersal fishes: a model application to shortspine thornyhead Sebastolobus alascanus
}

\author{
Christopher N. Rooper*, Michael H. Martin
}

Alaska Fisheries Science Center, National Marine Fisheries Service, 7600 Sand Point Way NE, Seattle, Washington 98115, USA

\begin{abstract}
Predicting the abundance of marine fishes based on habitat models is often difficult due to the presence of large numbers of zero observations. The objective of this study was to analyze the ability of a 2-stage model to predict the presence and abundance of a rockfish species, shortspine thornyhead Sebastolobus alascanus. The data used for these analyses were collected during bottomtrawl surveys of the Gulf of Alaska ecosystem from 1993 to 2007 and in the Aleutian Islands ecosystem from 1994 to 2006. The presence of shortspine thornyhead was predicted from the 5th and 95th percentiles of the cumulative distribution function resampled over depth and temperature. The results predicted shortspine thornyhead would not occur at depths $<176 \mathrm{~m}$ or $>671 \mathrm{~m}$, and presence or absence was correctly predicted at $86.3 \%$ of the trawl survey stations. Environmental variables were then used to model shortspine thornyhead abundance at stations where presence was predicted. The best-fitting model of abundance included the variables depth, local slope, thermocline temperature, shrimp catch per unit effort (CPUE), and an index of predation refuge. The model explained $72.4 \%$ of the variation in 1993-2005 Gulf of Alaska survey data and $73.7 \%$ of the variation in the 2007 data from the Gulf of Alaska. The model explained only $23.9 \%$ of the variation in shortspine thornyhead CPUE from the Aleutian Islands bottom-trawl surveys from 1994 to 2006. The habitat model included important variables for survival and growth in order to provide more biologically meaningful results than with other modeling methods.
\end{abstract}

KEY WORDS: Rockfish $\cdot$ Fish habitat $\cdot$ Fish distributions $\cdot$ Environmental variables $\cdot$ Alaska Resale or republication not permitted without written consent of the publisher

\section{INTRODUCTION}

The distributions of rare animals can be difficult to predict using simple habitat models because of the prevalence of zero-inflated distributions (Martin et al. 2005). Assuming animals are observed when present, a large number of observations of zero occurrences of the animal of interest at a site can be the result of 3 processes: (1) zero counts due to the site being outside the natural range of the animal; (2) zero counts due to the lack of appropriate habitat available at the site; and (3) zero counts in areas where the habitat is appropriate, but due to the patchiness or rarity of the organism, none were observed. Zero counts due to the first case are often thought to be the result of limiting factors in the environment on a large scale (temperature, salinity, etc.), while patchiness on a smaller scale can generally be thought of as related to resources available (food, refuge, etc.) (Guisan \& Thuiller 2005). It is important to treat zero counts from outside the range of the organism differently than zero counts within the range of the species, as these reflect different ecological processes. Two approaches are generally used in the presence of zero-inflated data: either modeling only the data where positive observations were found, or using a 2-stage model, where the presence or absence is modeled in the first step and then the abundance is modeled for those sites where presence was predicted.

Most 2-stage models use logistic regression to model presence or absence followed by a linear (multiple re- 
gression or general linear model) or non-parametric (general additive model) model to predict abundance (Welsh et al. 1996, Barry \& Welsh 2002). The general additive models or general linear models can quite effectively describe the data patterns and predict observations (Swartzman et al. 1992, Stoner et al. 2001, Walsh et al. 2004). However, the results of the analyses may be difficult to interpret in terms of the biology of the organism, and predictions of presence and abundance outside the region or years where the model was parameterized may be inaccurate. To provide more biologically meaningful results from these models, it would be preferable to utilize relationships based on the underlying processes affecting the organism's growth and survival; however, these are seldom measured directly.

Niche theory predicts that a population's abundance should change along a resource continuum that defines its habitat (Hutchinson 1957). These relationships between the environment and population abundance have been described by linear relationships, densitydependent functions, and dome-shaped curves (May 1973, Murawski \& Finn 1988, Friedlander \& Parrish 1998, Iles \& Beverton 2000). If these relationships can be parameterized, they should give robust predictions of an animal's abundance inside habitats of concern. It is important to produce accurate and biologically meaningful habitat models for marine fishes, as anthropogenic activities and climate change may impact fish populations and habitat utilization. However, predicting habitat use by marine fish species is an especially daunting task due to the difficulty of sampling many species, as well as the species-specific habitats inhabited by specific life-history stages. One group that has proved especially difficult is rockfishes in the northeast Pacific Ocean.

As a group, rockfish (Sebastes spp. and Sebastolobus spp.) comprise an important component of northeastern Pacific ecosystems. They are diverse, with 35 species represented in Alaskan waters. One of the most valuable rockfish species in Alaska is the shortspine thornyhead Sebastolobus alascanus. Habitat use by this species is generally not well known, but a vast amount of data has been collected on the distribution and abundance of this species and its feeding habits during resource-assessment bottom-trawl surveys in Alaska since 1980. Shortspine thornyhead are widely distributed along the Pacific rim from Baja California to Japan (Love et al. 2002). The species is long-lived (80 to $100 \mathrm{yr}$ ) and very slow-growing. They have an extended pelagic larval phase before settling to the seafloor as juveniles (Love et al. 2002). Little is known of the processes determining recruitment or dispersal patterns for this species in Alaska. In the Gulf of Alaska and Aleutian Islands there is no directed fish- ery for shortspine thornyhead, although they are taken as bycatch in longline and trawl fisheries directed at sablefish Anoplopoma fimbria and other rockfish. There has also been no recent evidence of large recruitment to the population, and consequently, the stock size and size structure of the population have been relatively stable since 1990 (North Pacific Fishery Management Council 2007).

The objective of the present study was to use a 2 -stage non-linear model for predicting the abundance of shortspine thornyhead. The advance in modeling presented here is that the habitat models were constructed based on the ecology of the organism, with an attempt to include important variables for survival and growth. This methodology was designed to provide more accurate, robust and biologically meaningful predictions than those developed from strictly statistical models such as general linear and additive analyses. A series of models were developed and parameterized based on the ecology of the shortspine thornyhead. The best-fitting model was used to predict data collected independently (both spatially and temporally) from the data set used for parameterization.

\section{MATERIALS AND METHODS}

Trawl survey data. The data used for these analyses were collected during bottom-trawl surveys of the Gulf of Alaska and Aleutian Islands ecosystems. The National Marine Fisheries Service (NMFS), Alaska Fisheries Science Center (AFSC), has conducted standard bottom-trawl surveys in these ecosystems since 1980 (Britt \& Martin 2001, Zenger 2004). The Gulf of Alaska bottom-trawl survey is conducted from the Islands of Four Mountains $\left(170^{\circ} \mathrm{W}\right)$ to Dixon Entrance $\left(133^{\circ} \mathrm{W}\right)$ (Fig. 1). Surveys were conducted triennially between 1993 and 2000 and biennially thereafter (Table 1). For this analysis, AFSC bottom-trawl data from 1993 to 2005 were combined across years. The 1993 bottom-trawl survey was the first for which accurate temperature at depth data were available for calculating water-column properties used in the modeling. The 2007 Gulf of Alaska bottom-trawl data and the 1994-2006 Aleutian Islands bottom-trawl data were also used as test data sets in this analysis (Table 1).

The Gulf of Alaska and Aleutian Islands bottomtrawl surveys utilize a poly Nor'Eastern high-opening bottom trawl with $24.2 \mathrm{~m}$ roller gear constructed with $36 \mathrm{~cm}$ rubber bobbins separated by $10 \mathrm{~cm}$ rubber disks (Stauffer 2004). Trawl tows were conducted at a target speed of $5.6 \mathrm{~km} \mathrm{~h}^{-1}$ (3 knots) for 15 or $30 \mathrm{~min}$. Bottom contact and net dimensions were recorded throughout each trawl tow using net mensuration equipment. For these analyses, records were only used if trawl perfor- 


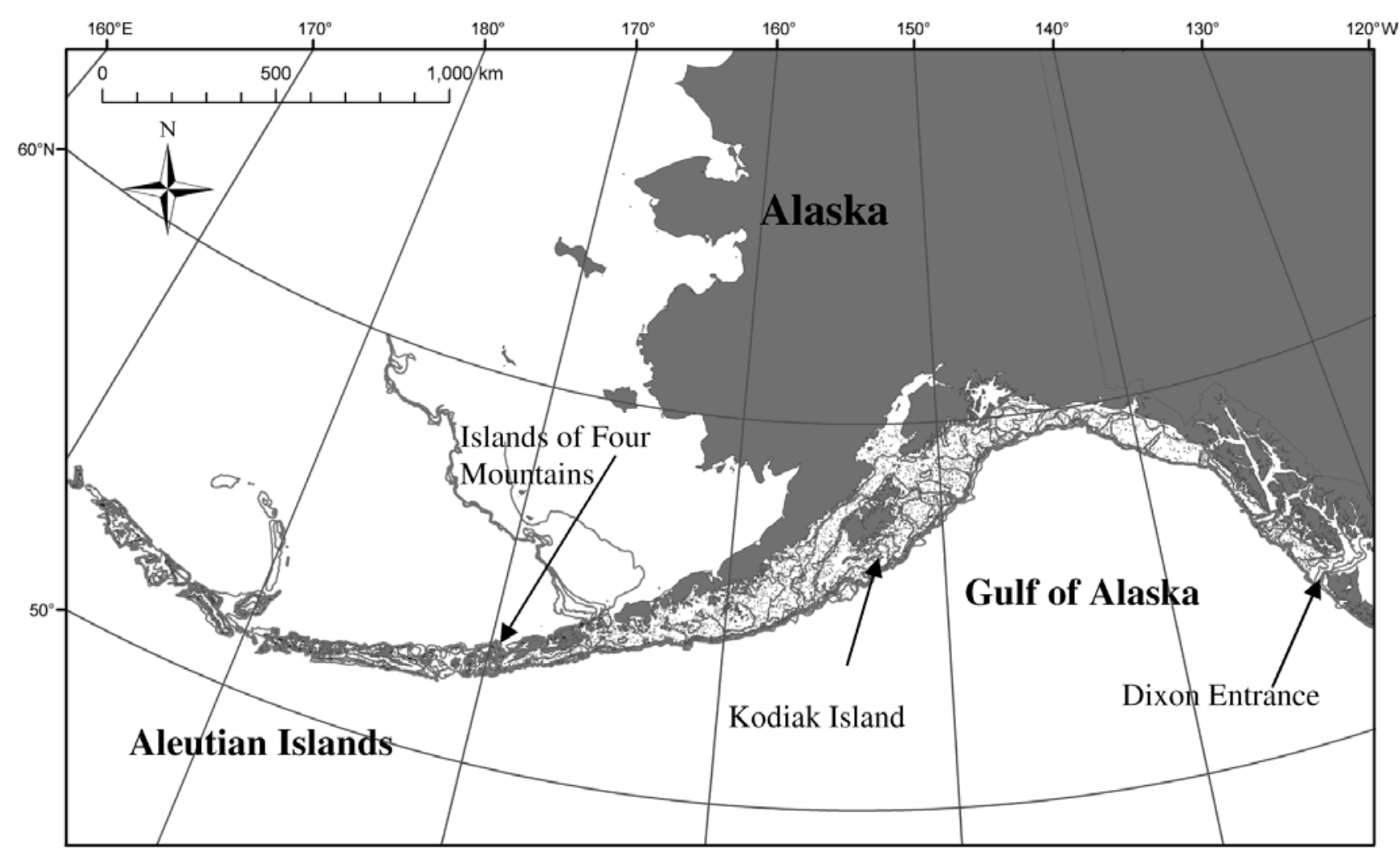

Fig. 1. Study area showing the Gulf of Alaska and Aleutian Islands ecosystems surveyed by the Alaska Fisheries Science Center biennial bottom-trawl survey. The Gulf of Alaska survey is conducted at stratified random stations in the area bounded by the Islands of Four Mountains and Dixon Entrance. The Aleutian Islands bottom-trawl survey is conducted from the Islands of Four Mountains west to the end of the Aleutian chain on the south and from $165^{\circ} \mathrm{W}$ to the west on the north side of the Aleutian chain.

Table 1. Number of satisfactory bottom-trawl survey tows (n) in each year for which all input data were collected. The model was parameterized with Gulf of Alaska survey data from 1993 to 2005 and tested against Gulf of Alaska survey data collected in 2007 and Aleutian Islands survey data collected from 1994 to 2006

\begin{tabular}{|llr|}
\hline Year & Ecosystem & $\mathrm{n}$ \\
\hline 1993 & Gulf of Alaska & 471 \\
1994 & Aleutian Islands & 371 \\
1996 & Gulf of Alaska & 702 \\
1997 & Aleutian Islands & 374 \\
1999 & Gulf of Alaska & 758 \\
2000 & Aleutian Islands & 409 \\
2001 & Gulf of Alaska & 455 \\
2002 & Aleutian Islands & 417 \\
2003 & Gulf of Alaska & 788 \\
2004 & Aleutian Islands & 412 \\
2005 & Gulf of Alaska & 818 \\
2006 & Aleutian Islands & 357 \\
2007 & Gulf of Alaska & 783 \\
Total & & 7115 \\
\hline
\end{tabular}

mance was satisfactory and if the distance fished, geographic position, average depth, and water temperature profile were recorded. Trawl tows were deemed satisfactory if the net opening was within a predetermined normal range, the roller gear maintained contact with the seafloor, and the net suffered little or no damage during the tow. Data from a total of 7115 bottom-trawl tows were used (Table 1).

All fish captured during a survey tow were sorted by species, counted and measured for total or fork length, and the total weight of each species in the catch was determined. For large catches, the total catch was estimated and subsampled for length data. Catch per unit effort (CPUE, no. ha-1) for shortspine thornyhead was calculated using the area swept computed from the net width for each tow multiplied by the distance towed recorded with GPS. Previous analyses indicate that juvenile and adult stages of shortspine thornyhead sampled by the bottom trawl do not have different distributions in Alaska (Rooper 2008), and therefore both life-history stages were combined for this analysis. Shortspine thornyhead catch data were transformed 
using natural log (CPUE + 1) prior to analyses, hereinafter shortened to CPUE. This transformation was chosen to minimize the bias due to observations of zero CPUE occurring in the second stage of modeling.

Stage 1: presence or absence prediction. The initial step for modeling the presence or absence $(R)$ of shortspine thornyhead in the trawl survey data was to determine tows that were outside the range of the species (zero values occurring because the station was outside the species' natural distribution) based on limiting factors (Guisan \& Thuiller 2005). Only data from the 1999, 2003 and 2005 bottom-trawl surveys were used to determine the species range, as these were the only years in which sampling was conducted at depths to at least $700 \mathrm{~m}$ and across the entire Gulf of Alaska region.

Limiting factors are typically variables that change a species' distribution gradually over a large change in the variable (Guisan \& Thuiller 2005); for example, changes in fish abundance over latitudinal gradients are typically gradual changes throughout most of a species range, with distinct limits beyond which the species is not typically found. In this case depth (D), temperature $(T)$, and geographic position (latitude and longitude) were considered viable candidates. However, the Gulf of Alaska and Aleutian Islands bottomtrawl surveys fall within the middle of the overall range (both from north to south and from west to east) of shortspine thornyhead (Love et al. 2002), so it is unlikely that geographic position had a strong influence on the presence or absence in this range. Therefore, only 2 environmental variables, depth and temperature, were included in this first stage of modeling shortspine thornyhead presence or absence. These were assumed to be likely limiting factors on the distribution of shortspine thornyhead within the survey area, as other research has suggested depth and temperature are primary organizing features for distributions of rockfish species (Weinberg 1994, Williams \& Ralston 2002, Tolimieri \& Levin 2006, Rooper 2008) and determinants of physiological processes (Harvey 2005). Continuous depth and temperature measurements were collected during each trawl tow using calibrated Brancker bathythermographs or SeaBird (SBE19 or SBE-39) microbathythermographs (Sea-Bird Electronics) attached to the headrope of the net. The average bottom depth and bottom temperature from each trawl tow was used to predict the presence or absence of shortspine thornyhead.

The cumulative distribution function (CDF) of shortspine thornyhead abundance was randomly resampled over the depth and temperature variables to determine the niche dimensions of the species. From the original sample of trawl tows from 1999, 2003, and 2005 (n = 2370), 1000 replicate tows were chosen (with replacement) and the 5th and 95th percentiles of the cumula- tive distribution function were computed for each variable (Fig. 2). This process was repeated 1000 times for each of the variables (depth and temperature). The mean 5th and 95th percentiles were computed for each variable and the trawl tows occurring outside this range (below the 5th or higher than the 95th percentiles for depth or temperature) were considered to be outside the niche of shortspine thornyhead and were predicted to have no shortspine thornyhead occurring in them $(R=0)$. Stations falling within the depth and temperature niche's of shortspine thornyhead were predicted to have shortspine thornyhead present $(R=1)$. The 5th and 95th percentiles of the cumulative distribution were chosen to eliminate potentially spurious data (such as depth, temperature or species identification that were recorded incorrectly) or outliers occurring at the fringes of the depth and temperature distributions of the species.

Stage 2: abundance model. The second stage of the modeling was designed to predict the abundance of
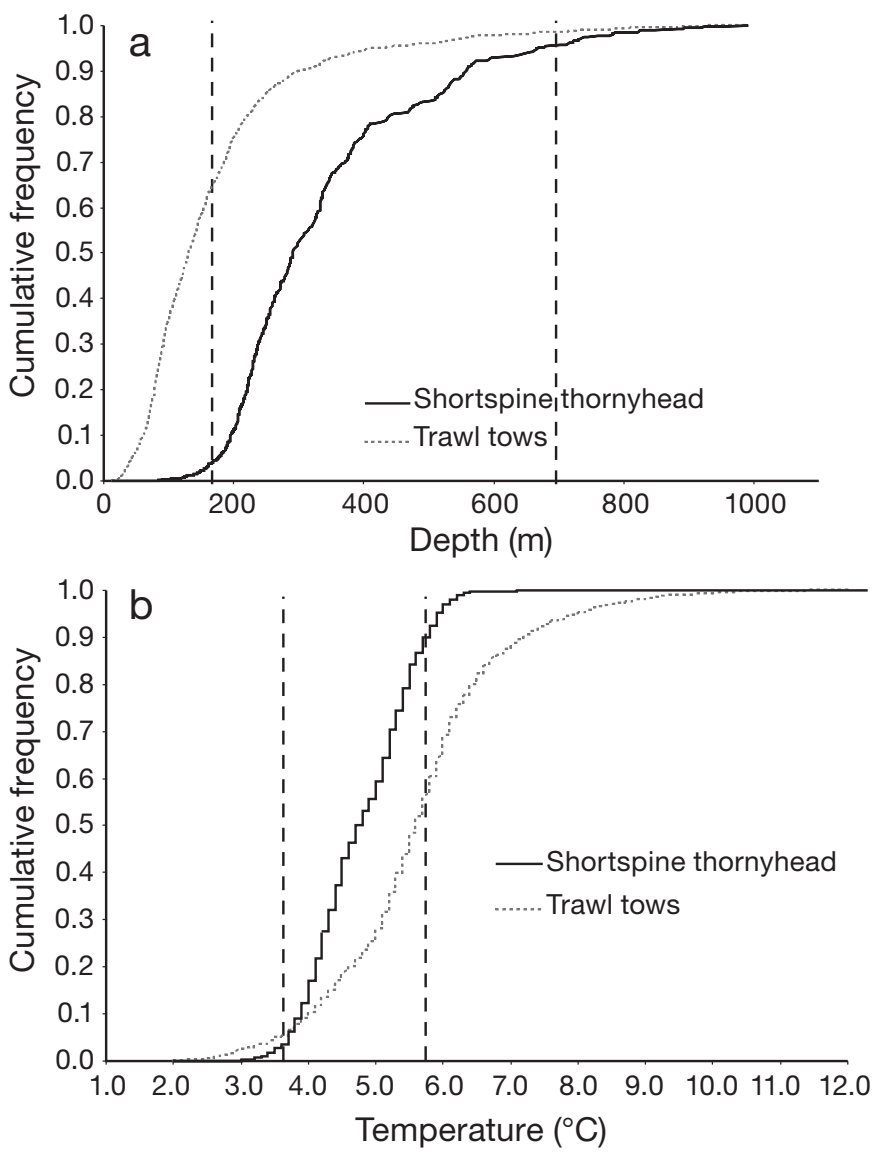

Fig. 2. Cumulative distribution function for shortspine thornyhead catch as a function of (a) depth and (b) temperature. Dashed lines indicate the calculated 5th and 95th percentiles for the data from resampling the 1999, 2003 and 2005 bottomtrawl surveys $(\mathrm{n}=2371)$ 
shortspine thornyhead at stations where they were predicted to be present. Seven resource variables (Guisan \& Thuiller 2005) were used to model shortspine thornyhead abundance, including the 2 predictors of presence or absence (depth and temperature), as well as habitat variables chosen for their potential importance to growth, survival and regulation of metabolism. The suite of variables included an index of local bottom slope $(B)$, thermocline depth $(S)$, thermocline temperature $(G)$, an index of predation refuge $(H)$, and an index of prey abundance $(P)$ (Table 2$)$.

The index of local bottom slope was calculated for each trawl survey station using bathymetry maps with depth contours in $100 \mathrm{~m}$ increments from 0 to $2000 \mathrm{~m}$ (derived from ETOPO 2' gridded elevation data). The bathymetry was kriged over the station grid for the Gulf of Alaska and the slope was calculated from this surface using ArcGIS spatial analyst tools. The local slope was extracted from this surface for each latitude and longitude pair at the midpoint of each bottomtrawl tow.

Water column stratification is often related to water column productivity (Whitney et al. 2005, Strom et al. 2006). For example, where the water column is wellmixed (small temperature difference between surface and deeper water and a deep or absent thermocline), upwelling may be occurring, indicating higher availability of nutrients for primary productivity in an area. Conversely, a shallow and strong thermocline could indicate nutrient-limited growth. In the present analysis, the water column stratification was estimated by the thermocline depth. The depth of the thermocline was estimated as the depth $(>1 \mathrm{~m})$ where the most rapid decrease in temperature (change in temperature/change in depth) occurred based on the data from the microbathythermograph during the setting of the net or downcast.

The thermocline temperature was defined as the temperature at the thermocline depth. This variable was used as a proxy for processes that are potentially related to water column productivity. For example, nutrient-rich upwelled water is generally colder than surface water, so a low thermocline temperature may reflect the potential for a phytoplankton bloom when the thermocline breaks down. The thermocline temperature generally became warmer as the trawl survey progressed through the summer, so this variable also reflected within-season changes in water column temperature. Because the trawl surveys generally progress from west to east in the Gulf of Alaska and from east to west in the Aleutian Islands, the thermocline temperature variable was a proxy for the geographic position of the trawl survey station. Thus, the thermocline temperature variable integrated the effect of geographic position of the bottom-trawl station, temporal changes in productivity over the summer and potential for production when stratification broke down.

Rocky, hard bottom substrates and benthic invertebrates are sources of refuge from predators and thus are presumed to be important in determining survival. Hard seafloor in Alaska is often covered by a combination of benthic invertebrates, including corals and sponges (Freese 2001), and rockfishes are often associated with these invertebrates (Rooper \& Boldt 2005, Rooper et al. 2007). The log-transformed CPUE of coral and sponge (combined) was used as an index of the amount of potential refuge from predation at each trawl tow site in the present analysis.

The final habitat variable used in the present analysis was shrimp abundance for each bottom-trawl tow. This was used as an index of the amount of prey available to shortspine thornyhead at the trawl survey station. Shrimp is a major component of the diet of shortspine thornyhead in the Gulf of Alaska (Yang et al. 2006). Shrimp of a number of taxa are captured in bottom-trawl tows, so the combined catch of shrimp (pandalidae, crangonidae, etc.) in each of the trawl tows was measured in $\mathrm{kg} \mathrm{ha}^{-1}$ and used as an index of prey abundance at that station.

To model shortspine thornyhead abundance, CPUE was estimated as a function of 7 habitat variables: depth $(D)$, temperature $(T)$, thermocline temperature

Table 2. Environmental variables used for modeling shortspine thornyhead presence or absence and abundance. $\mathrm{CPUE}=\mathrm{catch}$ per unit effort

\begin{tabular}{|lcccc|}
\hline Variable & Units & Definition & Index & Data source \\
\hline Shrimp abundance & $\mathrm{kg} \mathrm{ha}^{-1}$ & Shrimp (combined species) CPUE & Prey abundance & Bottom-trawl tow \\
Bottom temperature & ${ }^{\circ} \mathrm{C}$ & Average bottom temperature & Microbathythermograph \\
Bottom depth & $\mathrm{m}$ & Average bottom depth & Microbathythermograph \\
Local slope & $\% \mathrm{change}$ & Slope at each bottom-trawl station & Kriged bathymetry maps \\
Invertebrate index & $\mathrm{kg} \mathrm{ha}^{-1}$ & Combined CPUE of sponge and coral & Refuge from predation & Bottom-trawl tow \\
Thermocline depth & $\mathrm{m}$ & Depth of maximum change in temperature & Water column stratification & Microbathythermograph \\
Thermocline & ${ }^{\circ} \mathrm{C}$ & Temperature at the thermocline depth & Water column production & Microbathythermograph \\
temperature & & & & \\
& & & \\
\end{tabular}


$(G)$, thermocline depth $(S)$, local bottom slope $(B)$, the index of predation refuge $(H)$, and the prey abundance index $(P)$,

$\mathrm{CPUE}=R^{*}[f(D)+f(T)+f(G)+f(S)+f(B)+f(H)+f(P)+\varepsilon]$

where $R$ is presence (1) or absence (0) from the analysis of niche dimensions (Stage 1) and $\varepsilon$ is the error term. As in Rooper et al. (2005), the relationships between shortspine thornyhead CPUE and habitat variables were estimated using 1 of 3 equations. The most complex (having the most parameters) equation had 3 parameters and represented the response of CPUE as a dome-shaped function of the habitat variables, so that

$$
\mathrm{CPUE}_{h}=\alpha_{h}+\beta_{h} X_{h}+\varphi_{h} X_{h}^{2}
$$

Here, $X_{h}$ is habitat variable $h$, while $\beta_{h}, \phi_{h}$, and $\alpha_{h}$ are parameters fitted to the data. The next equation describes CPUE as a density-dependent function of the habitat variables, so that

$$
\mathrm{CPUE}_{h}=a_{h} X_{h} \exp ^{-b_{h} X_{h}}
$$

In this case, only 2 parameters, $a_{h}$ and $b_{h}$, are fit. The simplest equation (least parameters) predicted shortspine thornyhead abundance as proportional to the habitat variable $X_{h}$, so that

$$
\mathrm{CPUE}_{h}=c_{h} X_{h}
$$

where $C_{h}$ is the only parameter fit in the equation.

All components of CPUE were combined prior to fitting the parameters. For example, the initial (full) model for the analyses estimated 21 parameters, using the 3-parameter Eq. (2) for each of the 7 variables, so that

$$
\begin{aligned}
\mathrm{CPUE}= & \alpha_{D}+\beta_{D} X_{D}+\varphi_{D} X_{D}^{2}+\alpha_{T}+\beta_{T} X_{T}+\varphi_{T} X_{T}^{2}+ \\
& \alpha_{G}+\beta_{G} X_{G}+\varphi_{G} X_{G}^{2}+\alpha_{S}+\beta_{S} X_{S}+\varphi_{S} X_{S}^{2}+ \\
& \alpha_{B}+\beta_{B} X_{B}+\varphi_{B} X_{B}^{2}+\alpha_{H}+\beta_{H} X_{H}+\varphi_{H} X_{H}^{2}+ \\
& \alpha_{P}+\beta_{P} X_{P}+\varphi_{P} X_{P}^{2}+\varepsilon
\end{aligned}
$$

All 21 parameters for the suite of habitat variables were fit simultaneously.

The errors, $\varepsilon$, were then assumed to be distributed log-normally and model parameters were estimated by minimizing the negative log-likelihood (Hilborn \& Mangel 1997),

$$
L=\sum\left[\log (\sigma)+\frac{1}{2} \log (2 \pi)+\frac{(Y-\hat{Y})^{2}}{2 \sigma^{2}}\right]
$$

where $\sigma$ is estimated analytically by

$$
\sigma=\sqrt{\frac{\sum(Y-\hat{Y})^{2}}{n-1}}
$$

$L$ is the negative log-likelihood, $Y$ are the observed CPUE data and $\hat{Y}$ are the predicted values.
Models were reduced by sequentially removing 1 parameter for a variable (e.g. the depth relationship was changed from Eq. 2 to Eq. 3) and parameters were refit. In the next step, another parameter was removed for the variable (e.g. the depth relationship was changed from Eq. 3 to Eq. 4) and this was repeated until the variable was no longer included in the equation (all parameters were removed). Then the process was repeated for the next 6 variables. The models from this round of modeling were compared using Akaike's information criterion (AIC) for non-nested models to determine the best-fitting model:

$$
\mathrm{AIC}=2 L+2 p
$$

where $p$ is the number of parameters in the model (Akaike 1992). The best of this round of models was then evaluated against the 21-parameter model. The rounds of model fitting were repeated until the reduction in the number of parameters or elimination of variables resulted in no reduction in the AIC score and this final model was deemed best for the data set analyzed. The evidence ratios (Burnham \& Anderson 2002) were also calculated for each model $\left(m_{i}\right)$ relative to the best model $\left(m_{\min }\right)$ using the formula:

$$
\text { evidence }_{i}=w_{\min } / w_{i}
$$

where

and

$$
w_{i}=\frac{\exp \left(-0.5^{*} \Delta_{i}\right)}{\sum_{m=1}^{M} \exp \left(-0.5^{*} \Delta_{m}\right)}
$$

$$
\Delta_{i}=\mathrm{AIC}_{i}-\mathrm{AIC}_{\min }
$$

The correlation between the observed and predicted values was used to determine the percentage of variance in the CPUE data set explained by the model. Deviations (observed values minus predicted values) for the model were explored through examination of qqnorm plots and residuals via a geographic information system (GIS) to examine spatial patterns. A Kolmogorov-Smirnov goodness-of-fit test was used to determine if the residuals violated the assumption of normality.

The relative contribution of each of the variables to the best-fitting model was also calculated by removing a variable, refitting the model and then dividing the sum of the negative log-likelihood with the variable removed by the sum of the negative log-likelihood of the bestfitting model. The contributions were then scaled to the most important variable by calculating the change in the negative log-likelihood with each variable removed as a percentage of the variable with the largest change in negative log-likelihood when it was removed.

Model cross-validation. Once a best-fitting model was determined for the 1993-2005 Gulf of Alaska trawl survey data, the model was tested on shortspine 
thornyhead catch data from the 2007 Gulf of Alaska trawl survey and from the 1994-2006 Aleutian Islands bottom-trawl surveys. For each test data set, catch data, depth, temperature, stratification index, thermocline temperature, index of seafloor slope, predation refuge index, and prey abundance were compiled into a matrix. The parameters from the best-fitting model of the 1993-2005 Gulf of Alaska data were used to predict the shortspine thornyhead distribution for 2007 Gulf of Alaska data and the 1994-2006 data for the Aleutian Islands. The error of the model was calculated as the observed CPUE minus the predicted CPUE using the 1993-2005 model and parameters and the percentage of explained variance in the test data was estimated. Deviations (observed values minus predicted values) for the model were explored through examination of qqnorm plots and GIS plots of residuals to examine spatial patterns. A Kolmogorov-Smirnov goodness-of-fit test was used to determine if the residuals violated the assumption of normality.

\section{RESULTS}

Shortspine thornyhead were captured at $23.8 \%$ of the tows in the 1993-2005 Gulf of Alaska bottom-trawl surveys, $24.5 \%$ of the tows in the 2007 bottom-trawl survey, and $16.7 \%$ of the 1994-2006 Aleutian Islands bottom-trawl survey tows. Catches of shortspine thornyhead ranged from 0 to 434 fish ha ${ }^{-1}$. Trawl survey data were collected at depths from 16 to $992 \mathrm{~m}$ in the Gulf of Alaska, and from 20 to $488 \mathrm{~m}$ in the Aleutian Islands (Table 3 ). Although bottom temperatures ranged from 0.8 to $12.5^{\circ} \mathrm{C}$ in the Gulf of Alaska (mean $=5.5^{\circ} \mathrm{C}$ ), the average temperature was $\sim 1^{\circ} \mathrm{C}$ warmer than in the Aleutian Islands (mean $=4.2^{\circ} \mathrm{C}$ ), where temperatures ranged only from 3.0 to $7.3^{\circ} \mathrm{C}$ (Table 3 ). The stations were spread evenly across the Gulf of Alaska and Aleutian Islands, with a denser station pattern in southeastern Alaska due to the narrower continental shelf. The thermocline depth ranged from just below the surface $(<5 \mathrm{~m})$ to deeper than $400 \mathrm{~m}$ in both ecosystems (Table 3 ). The temperature at the thermocline depth ranged from 2.6 to $16.4^{\circ} \mathrm{C}$ in the Gulf of Alaska and from 3.2 to $10.6^{\circ} \mathrm{C}$ in the Aleutian Islands (Table 3). The catch of prey species (shrimp) ranged from 0 to $26.0 \mathrm{~kg} \mathrm{ha}^{-1}$ in the Gulf of Alaska and from 0 to $56 \mathrm{~kg} \mathrm{ha}^{-1}$ in the Aleutian Islands (Table 3). The local slope ranged from 0 to $20.4 \%$ in the Gulf of Alaska and up to $15.1 \%$ in the Aleutian Islands (Table 3), with the majority of deeper tows occurring near the shelf break (an area of increased slope). The catch of invertebrates ranged from 0 to $7307 \mathrm{~kg} \mathrm{ha}^{-1}$, with the highest individual catch occurring in the Gulf of Alaska (Table 3). However, the average catch of invertebrates
Table 3. Mean (median) and range of values of environmental variables used for modeling shortspine thornyhead presence or absence and abundance for the Gulf of Alaska (19932007) and Aleutian Islands (1994-2006) data sets

\begin{tabular}{|lccc|}
\hline Variable & Statistic & $\begin{array}{c}\text { Gulf of } \\
\text { Alaska }\end{array}$ & $\begin{array}{c}\text { Aleutian } \\
\text { Islands }\end{array}$ \\
\hline Shrimp & Mean (median) & $0.29(0)$ & $0.05(0)$ \\
abundance & Minimum & 0 & 0 \\
& Maximum & 25.97 & 55.97 \\
Bottom & Mean (median) & $5.5(5.5)$ & $4.2(4.2)$ \\
temperature & Minimum & 0.8 & 3.0 \\
& Maximum & 12.5 & 7.3 \\
Bottom depth & Mean (median) & $160(130)$ & $191(164)$ \\
& Minimum & 16 & 20 \\
Local slope & Maximum & 992 & 488 \\
& Mean (median) & $1.13(0)$ & $2.95(2.30)$ \\
Invertebrate & Minimum & 0 & 0 \\
index & Maximum & 20.42 & 15.14 \\
& Mean (median) & $3.45(0)$ & $14.1(0.8)$ \\
Thermocline & Minimum & 0 & 0 \\
depth & Maximum & 7.307 & 1.106 \\
& Mean (median) & $25.2(20.5)$ & $39.8(22.9)$ \\
Thermocline & Minimum & 1.2 & 1.4 \\
temperature & Maximum & 420.1 & 452.7 \\
& Minimum & $8.3(8.3)$ & $5.5(5.2)$ \\
& Maximum & 2.6 & 3.2 \\
& 16.4 & 10.6 \\
\hline
\end{tabular}

was an order of magnitude higher in the Aleutian Islands (mean $=14.1 \mathrm{~kg} \mathrm{ha}^{-1}$ ) than the Gulf of Alaska (mean $=3.45 \mathrm{~kg} \mathrm{ha}^{-1}$ ). Cross-correlations among explanatory variables were not large, except for the bottom-temperature variable, which was correlated with depth, local slope, and thermocline temperature (Table 4). The other important correlation was between depth and local slope (Table 4). Scatterplots of the raw data indicated depth and local slope should be strongly related to shortspine thornyhead catch, while the other variables exhibited less clear relationships with shortspine thornyhead CPUE (Fig. 3).

\section{Model parameterization: 1993-2005 Gulf of Alaska data}

The model predicted shortspine thornyhead presence or absence fairly well (Table 5). The model predicted that $<10 \%$ of shortspine thornyhead would occur at depths $<176 \mathrm{~m}$ or $>671 \mathrm{~m}$ (Fig. 2). The model predicted that $90 \%$ of shortspine thornyhead would occur at temperatures between 3.7 and $5.9^{\circ} \mathrm{C}$ (Fig. 2). The environmental variables predicted shortspine thornyhead could potentially occur at 1116 trawl survey stations ( $28 \%$ of the total trawl survey stations). However, shortspine thornyhead occurred at only 761 (68\%) of these 
Table 4. Correlations (r) among habitat variables for the combined Gulf of Alaska (1993-2007) and Aleutian Islands (1994-2006) data sets $(\mathrm{n}=7115)$

\begin{tabular}{|c|c|c|c|c|c|c|}
\hline & $\begin{array}{l}\text { Thermo- } \\
\text { cline depth }\end{array}$ & $\begin{array}{c}\text { Shrimp } \\
\text { abundance }\end{array}$ & $\begin{array}{l}\text { Bottom tem- } \\
\text { e perature }\end{array}$ & $\begin{array}{c}\text { Bottom } \\
\text { depth }\end{array}$ & $\begin{array}{l}\text { Local } \\
\text { slope }\end{array}$ & $\begin{array}{l}\text { Inverte- } \\
\text { brate index }\end{array}$ \\
\hline $\begin{array}{l}\text { Shrimp } \\
\text { abundance }\end{array}$ & -0.04 & & & & & \\
\hline $\begin{array}{l}\text { Bottom } \\
\text { temperature }\end{array}$ & $e^{-0.16}$ & 0.04 & & & & \\
\hline Bottom depth & 0.13 & 0.04 & -0.42 & & & \\
\hline Local slope & 0.09 & -0.09 & -0.33 & 0.42 & & \\
\hline $\begin{array}{l}\text { Invertebrate } \\
\text { index }\end{array}$ & 0.09 & -0.02 & -0.26 & 0.09 & 0.20 & \\
\hline $\begin{array}{l}\text { Thermocline } \\
\text { temperature }\end{array}$ & $e^{-0.32}$ & 0.13 & 0.58 & 0.07 & -0.13 & -0.26 \\
\hline
\end{tabular}

were found in Shelikof Trough, a deep gully to the west of Kodiak Island (Fig. A1, Appendix 1 available as Supplementary Material at www.int-res. com/articles/suppl/m379p253_app.pdf). The under-predictions of CPUE were broadly distributed near the continental shelf break, south of Prince William Sound and Kodiak Island (Fig. A1). Based on these modeling results, the predicted habitat niche of shortspine thornyhead may be found in a narrow band along the continental shelf break in the Gulf of Alaska. stations (Table 5). Shortspine thornyhead also occurred at 190 stations where the model predicted none would be found. Overall, the presence or absence of shortspine thornyhead was correctly predicted at $86.3 \%$ of the trawl survey stations by the model.

The best-fitting model for shortspine thornyhead abundance had 10 parameters and included only 5 of the original 7 habitat variables (Table 6). Shortspine thornyhead abundance was not significantly related to the thermocline depth, or the bottom temperature, as these 2 variables were not included in the best-fitting model. The relationship between shortspine thornyhead CPUE and temperature at the thermocline depth was represented by the 3-parameter equation in the best-fitting model (Fig. 4). The relationships between shortspine thornyhead CPUE and depth, local slope and shrimp CPUE were represented by the 2-parameter equation in the best-fitting model (Fig. 4). Shortspine thornyhead abundance decreased linearly with invertebrate abundance. Shortspine thornyhead abundance increased with increasing density of shrimp from 4 to $8 \mathrm{~kg} \mathrm{ha}^{-1}$ (Fig. 4). Shortspine thornyhead CPUE increased at local slopes up to a peak at $7.5 \%$ and at a depth of $400 \mathrm{~m}$ (Fig. 4). The most important variable in terms of its contribution to the reduction in variance was depth, followed by thermocline temperature, and local slope (Table 6). The shrimp CPUE and invertebrate index variables had small but significant contributions to the final model. The evidence ratios followed a similar pattern.

The best-fitting 2-stage model explained $72.4 \%$ of the variation in 1993-2005 bottom-trawl survey catches of shortspine thornyhead (Fig. 5). The deviations (observed CPUE minus predicted CPUE) from the bestfitting model were marginally significantly different from normal ( $p=0.04$ ) according to the KolmogorovSmirnov goodness-of-fit test. However, the residuals did not appear to seriously violate the assumption of log-normal distribution of errors (Fig. 6). Most of the observed negative errors (over-prediction of CPUE)

\section{Model testing: 2007 Gulf of Alaska data}

The presence and absence of shortspine thornyhead was accurately predicted for the 2007 bottom-trawl survey stations using the depth and temperature values developed from the random resampling of the cumulative frequency distributions of CPUE from the 1993-2005 Gulf of Alaska bottom-trawl surveys (Table 5). The presence or absence was correctly predicted at $88.6 \%$ of the bottom-trawl stations in the 2007 Gulf of Alaska bottom-trawl survey.

Using the parameters from the 2-stage model developed from the 1993-2005 data, the 2007 trawl-survey catches were predicted using the 5 environmental variables (depth, local slope, shrimp CPUE, thermocline temperature and invertebrate index). The 19932005 model parameters explained $73.7 \%$ of the variation in the 2007 shortspine thornyhead catch data (Fig. 5). Residual patterns were similar for both the 2007 data and the 1993-2005 data for which the model was parameterized (Figs. 6 \& A1). The KolmogorovSmirnov goodness-of-fit test indicated the residuals were normally distributed ( $\mathrm{p}>0.05)$.

\section{Model testing: 1994-2006 Aleutian Islands data}

The presence and absence of shortspine thornyhead was also relatively accurately predicted for the 1994-2006 Aleutian Islands bottom-trawl survey stations using the 1993-2005 Gulf of Alaska bottom-trawl surveys analysis (Table 5). The presence or absence was correctly predicted at $73.9 \%$ of the bottom-trawl stations in the 1994-2006 Aleutian Islands bottomtrawl survey. The lower percentage of sites predicted correctly in the Aleutian Islands appeared to be primarily a result of an increased percentage of sites where shortspine thornyhead were predicted to be present, but in fact were not observed. 

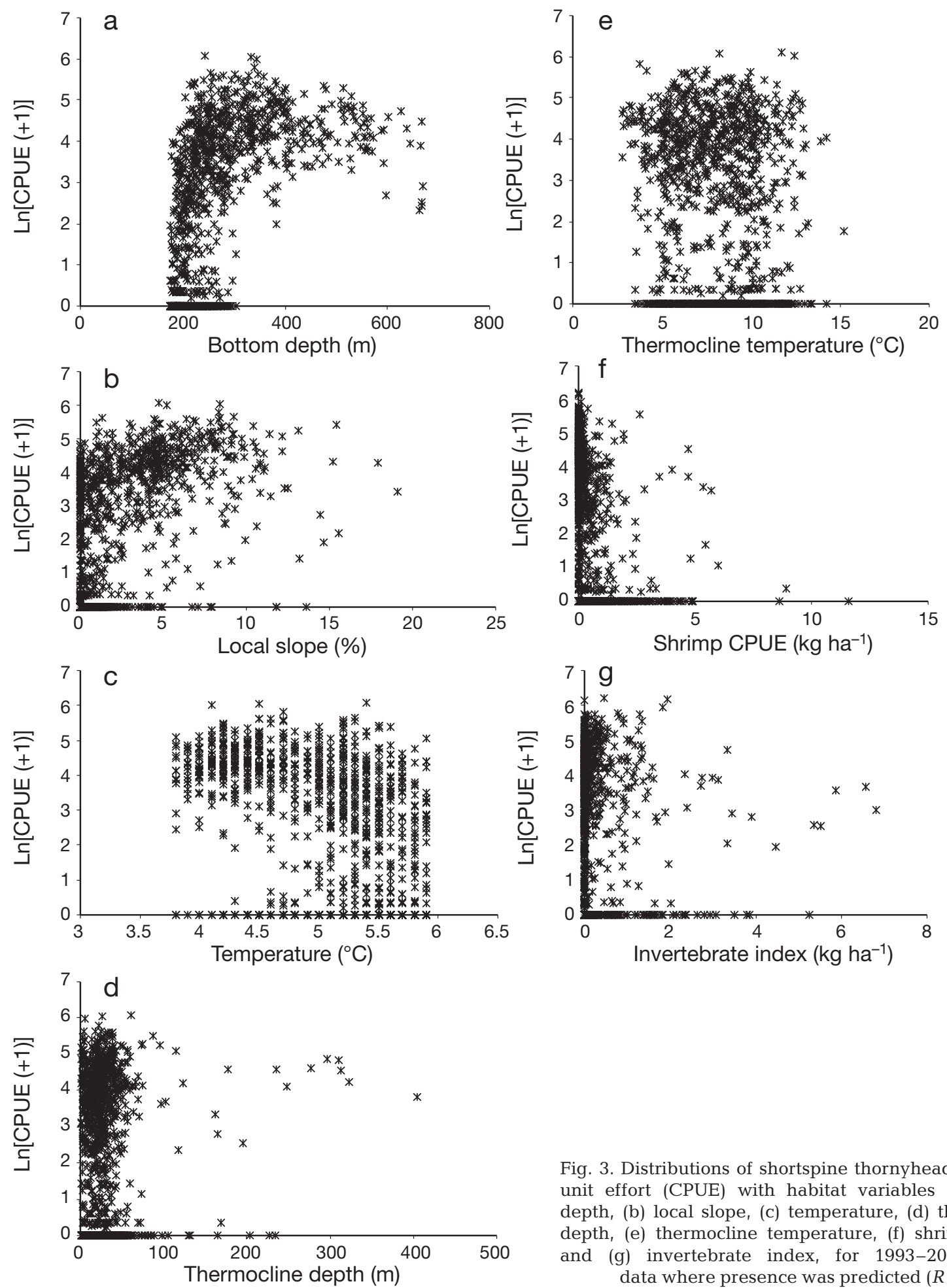

Fig. 3. Distributions of shortspine thornyhead catch per unit effort (CPUE) with habitat variables (a) bottom depth, (b) local slope, (c) temperature, (d) thermocline depth, (e) thermocline temperature, (f) shrimp CPUE, and (g) invertebrate index, for 1993-2005 survey data where presence was predicted $(R=1)$

Using the parameters from the 2-stage model developed from the 1993-2005 Gulf of Alaska data, the 1994-2006 Aleutian Island trawl-survey catches were predicted using the 5 environmental variables (depth, local slope, shrimp CPUE, thermocline temperature and invertebrate index). The 1993-2005 model parameters explained only $23.9 \%$ of the variation in the Aleutian Island catches of shortspine thornyhead (Fig. 5). The model significantly overpredicted the CPUE of shortspine thornyhead where only small catches were ob- 
Table 5. Predicted and observed presence or absence of shortspine thornyhead based on the prediction model. GOA = Gulf of Alaska

\begin{tabular}{|c|c|c|c|c|c|c|}
\hline & \multicolumn{2}{|c|}{ GOA data 1993-2005 } & \multicolumn{2}{|c|}{ GOA data 2007} & \multicolumn{2}{|c|}{ Aleutian Islands 1994-2006 } \\
\hline & $\begin{array}{l}\text { Predicted } \\
\text { present }\end{array}$ & $\begin{array}{c}\text { Predicted } \\
\text { absent }\end{array}$ & $\begin{array}{l}\text { Predicted } \\
\text { present }\end{array}$ & $\begin{array}{l}\text { Predicted } \\
\text { absent }\end{array}$ & $\begin{array}{l}\text { Predicted } \\
\text { present }\end{array}$ & $\begin{array}{l}\text { Predicted } \\
\text { absent }\end{array}$ \\
\hline Observed present & 761 & 190 & 157 & 35 & 285 & 106 \\
\hline Observed absent & 355 & 2686 & 54 & 537 & 505 & 1444 \\
\hline
\end{tabular}

Table 6. Full model and best-fitting model (with 10 parameters and with each variable sequentially removed) for predicting shortspine thornyhead catch per unit effort (CPUE). Par = number of parameters, AIC $=$ Akaike's information criterion, $\mathrm{r}^{2}=$ correlation between predicted and observed CPUE, $D=$ depth, $T=$ temperature, $G=$ thermocline temperature, $S=$ thermocline depth, $B=$ local bottom slope, $H=$ index of predation refuge, $P=$ prey abundance index. The evidence ratio (Burnham $\&$ Anderson 2002 ) is relative to the best-fitting model

\begin{tabular}{|lcccccc|}
\hline Model & Par & AIC & $\mathrm{r}^{2}$ & Variables & $\begin{array}{c}\text { Evidence ratio } \\
\text { Relative contribution } \\
\text { of missing variable }\end{array}$ \\
\hline Full model & 21 & 5939.9 & 0.719 & $D, T, G, S, B, H, P$ & $5.14 \times 10^{8}$ \\
Best-fitting model & 10 & 5930.8 & 0.724 & $D, G, B, P, H$ & 1.00 & $1.36 \times 10^{73}$ \\
Best-fitting model (without $D$ ) & 8 & 6101.2 & 0.639 & $G, B, P, H$ & 1.00 \\
Best-fitting model (without $G$ ) & 7 & 6047.9 & 0.664 & $D, B, P, H$ & $3.46 \times 10^{49}$ & 0.69 \\
Best-fitting model (without $B$ ) & 8 & 6008.5 & 0.685 & $D, G, P, H$ & $7.16 \times 10^{32}$ & 0.46 \\
Best-fitting model (without $P$ ) & 8 & 5938.6 & 0.720 & $D, G, B, H$ & 325.31 & 0.05 \\
Best-fitting model (without $H$ ) & 9 & 5931.9 & 0.723 & $D, G, B, P$ & 1.05 & 0.01 \\
\hline
\end{tabular}

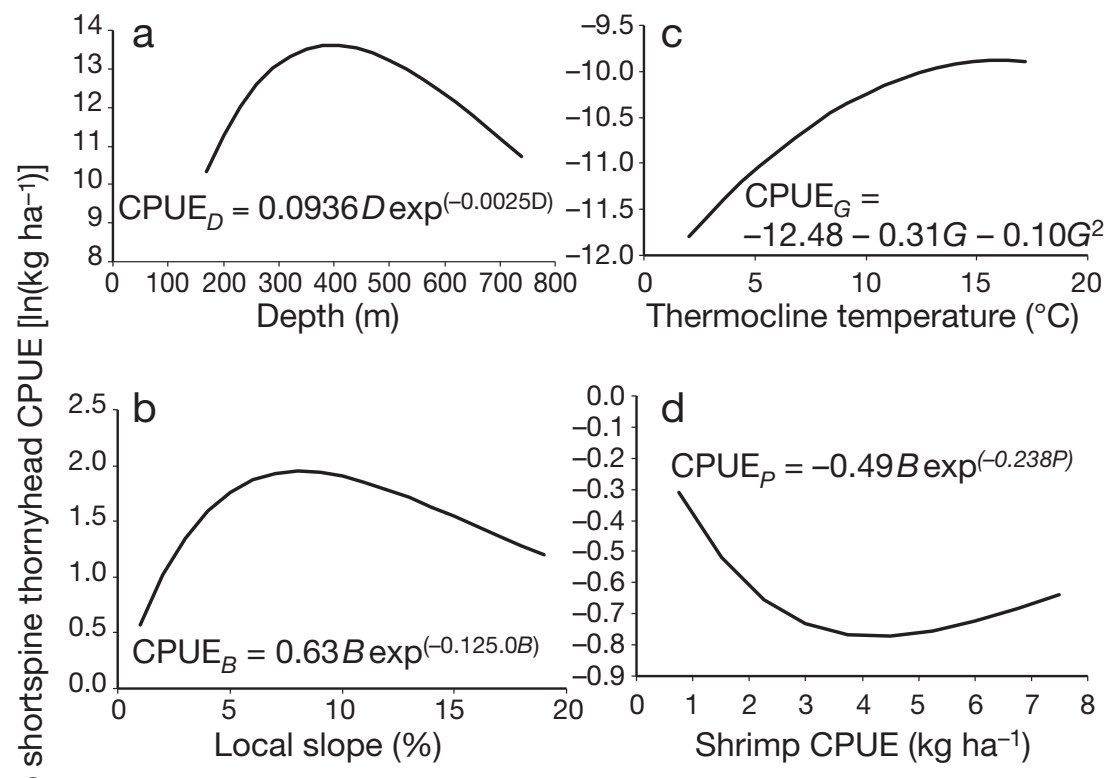

Fig. 4. Predicted relationships between shortspine thornyhead abundance and the 5 habitat variables, (a) bottom depth $(D)$, (b) local slope $(B)$, (c) thermocline temperature $(G),(d)$ shrimp CPUE $(P)$, and (e) invertebrate index $(H)$, included in the bestfitting model of shortspine thornyhead abundance from 1993-2005 bottom-trawl surveys. Equations and best-fitting parameters are given for each habitat variable. CPUE $=$ catch per unit effort served, leading to a large number of negative residuals throughout the Aleutian Islands (Appendix 1, Fig. A2). Residual patterns from the Aleutian Islands data were dissimilar to both the other data sets (Fig. 6); however, the Kolmogorov-Smirnov goodness-of-fit test indicated the residuals did not significantly depart from a normal distribution $(p>0.05)$.

\section{DISCUSSION}

Very few studies have been published regarding the habitat requirements or even the biology of shortspine thornyhead. Previous research on the density of shortspine thornyhead indicates that their abundance increases with depth to $>1000 \mathrm{~m}$ (Else et al. 2002, Lauth et al. 2004b). However, Else et al. (2002) only sampled to $355 \mathrm{~m}$ and in the Lauth et al. (2004a) study, shortspine thornyhead and longspine thornyhead Sebastolobus altivelis were not distinguished. Longspine thornyhead is known to have a deeper depth distribution than shortspine thornyhead (Jacobson \& Vetter 
a 1993-2005 Gulf of Alaska data
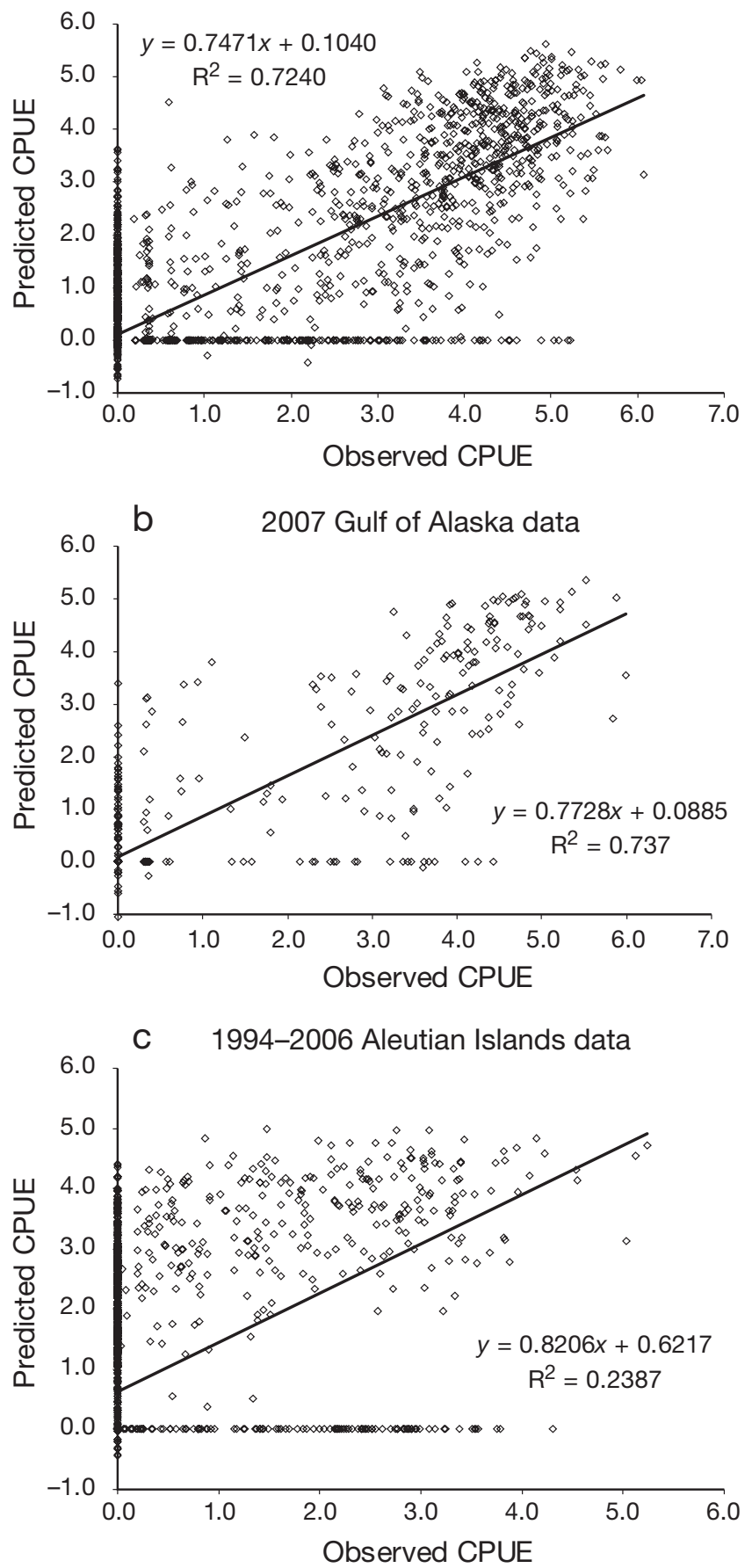

Fig. 5. Predicted and observed catch per unit effort (CPUE) for shortspine thornyhead for (a) the best-fitting model (19932005 data) and the test data for (b) 2007 data and (c) $1994-$ 2006 Aleutian Islands data

1996, Love et al. 2002). In Gulf of Alaska survey trawls, longspine thornyhead are found at depths beginning around $700 \mathrm{~m}$ and increasing to the deepest depths sampled (1000 m) (Britt \& Martin 2001).

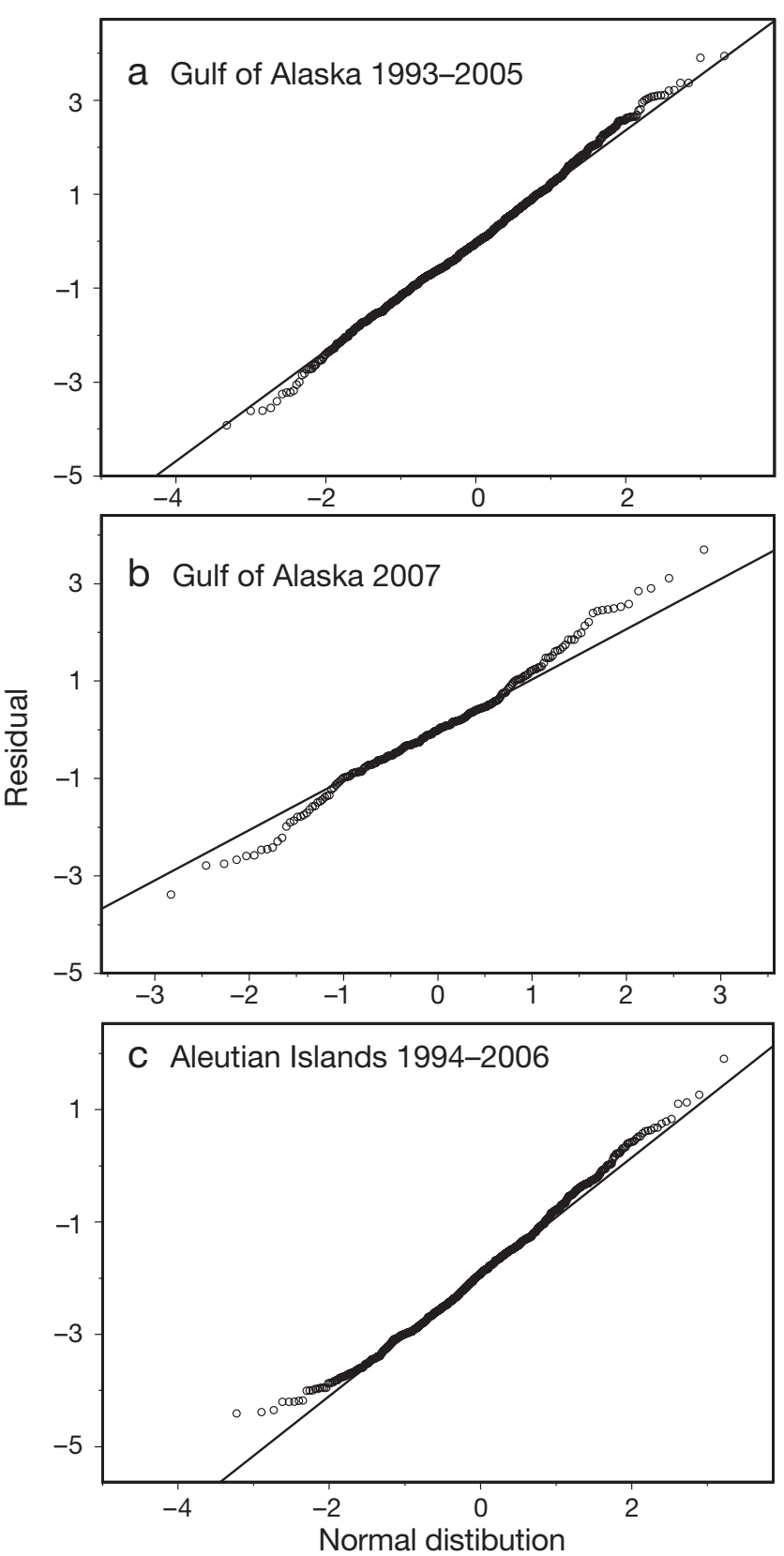

Fig. 6. Quantile-quantile plots of residuals from observed and predicted shortspine thornyhead catch per unit effort (CPUE) where they were predicted to be present $(R=1)$ against the quantiles of the normal distribution. For (a) 1993-2005 Gulf of Alaska data, predicted data were generated from the best-fitting model of shortspine thornyhead CPUE in the Gulf of Alaska. For (b) 2007 Gulf of Alaska and (c) 1994-2006 Aleutian Islands data, predicted data were generated from the best-fitting model of shortspine thornyhead from Gulf of Alaska 1993-2005 data

The results of the present analysis are consistent with those of Else et al. (2002) in finding little influence of the presence of invertebrates on shortspine thornyhead distribution. There are somewhat contradictory results 
in the affinities for hard substrate areas found for shortspine thornyheads from Oregon and Alaska studies. Video observations in Alaska have shown that shortspine thornyhead are more abundant on hard substrate (Else et al. 2002), while in Oregon and along the US west coast, shortspine thornyhead are typically found on featureless, sedimentary substrate (Stein et al. 1992, Jacobson \& Vetter 1996, Lauth et al. 2004b) at deeper depths and in both rock and mud habitat in shallower depths (Pearcy et al. 1989). The model results from the present study are somewhat counterintuitive, as the abundance of shortspine thornyhead decreased with increasing catch of invertebrates in the trawl tows. The effect of invertebrates was weak in the model, but could be due to either an aversion to hard substrates (where sponge and coral are more likely to be found) as suggested by the previous research on the US west coast, or decreased catchability of shortspine thornyhead in the trawl net over hard-bottom substrate. Regardless, our results are consistent with those of other researchers who have suggested depth is a much more important factor than substrate in determining shortspine thornyhead abundance.

Temperature was one of the least important variables in the present analysis of shortspine thornyhead abundance, but was very important in the prediction of presence or absence of shortspine thornyhead. This is different from the majority of studies of marine fish, where temperature often influences the abundance of a species (Murawski \& Finn 1988, Swartzman et al. 1992, Rooper et al. 2005). The importance of temperature in controlling metabolism and growth may be limited in the case of shortspine thornyhead, as bottom water temperature varied only by $<3^{\circ} \mathrm{C}$ throughout the range of depths inhabited by the species. This would suggest that shortspine thornyhead growth may be controlled by prey abundance in a fairly constant environment. There was only weak evidence for this in the results from the present analysis where shrimp abundance at a site had a negative influence on the abundance of shortspine thornyhead, but the effect was less negative at higher shrimp abundances. Even so, the significance of the effect was not very large and the presence of zero shrimp at a site had a net zero effect on shortspine thornyhead CPUE.

It is difficult to determine the exact relationships between bottom temperature, depth and local slope and shortspine thornyhead abundance, as these variables were somewhat confounded in the model. Areas of high slope tended to occur near areas of deeper depths. The internal correlations among the explanatory variables prevented assessment of their impacts individually. An issue of accuracy arises when considering the slope variable, because it was extracted from a fairly large-scale bathymetry database. A better variable for determining local slope could have been acquired from the ship's echosounder at the actual site of the bottomtrawl tow. However, this information was unavailable. Unfortunately, most of these variables (including shortspine thornyhead abundance) could be considered only indices of the true variable and the model would no doubt be improved by collection of specific and accurate data. For example, an accurate depiction of the prey field including all species of shortspine thornyhead prey could potentially provide a better result than the index (shrimp abundance) used here.

The prediction of shortspine thornyhead distribution was very successful for the test data set collected in 2007 in the Gulf of Alaska, but was not as successful when applied outside the region in the Aleutian Islands. Even when the Aleutian Islands data were independently fitted using the method applied to the 1993-2005 Gulf of Alaska data, the best model could only explain $35.7 \%$ of the variance in shortspine thornyhead data. Part of the failure in the Aleutian Islands may be some inherent differences in the bottomtrawl survey design in this ecosystem. For example, the Aleutian Islands bottom-trawl survey extends only to $500 \mathrm{~m}$ depth, which left a significant portion of the shortspine thornyhead habitat unsampled. It is known from other systems that densities of shortspine thornyhead are more variable in depths $<450 \mathrm{~m}$ (Lauth et al. 2004b), which could account for some of the unexplained variability in the model. Additionally, there is a significant ecological break that occurs in the Aleutian Islands west of Samalga Pass, where both the physical oceanography and biological characteristics of the system change (Ladd et al. 2005, Logerwell et al. 2005). This may also contribute to the inability of the Gulf of Alaska model to perform adequately in the Aleutian Islands. The diet of shortspine thornyhead in the Aleutian Islands appears to be somewhat different than in the Gulf of Alaska, consisting mainly of fish with a much lower consumption rate of shrimp (Yang 2003). There may also be unexplained differences between the 2 ecosystems and the role of shortspine thornyhead within their fish communities that may explain both differences found between the Aleutian Islands and the Gulf of Alaska, as well as differences in shortspine thornyhead distribution noted for the US west coast.

The underlying principles of the modeling presented here are based on the assumption that factors limiting shortspine thornyhead abundance are related to the availability of some resources. In theory, fish abundance should be related to a variety of resources that optimize survival and growth. This may also be an advantage of this modeling method over traditional methods, as the relationship between abundance and environmental variables is described by a series of shapes that are consistent with ecological theory. 
Another advantage of this method is that zero counts occurring from different ecological processes are treated (and modeled) differently. However, this modeling method may not be appropriate for all data sets. The data we used to model shortspine thornyhead abundance still contained $32 \%$ zero counts at sites where presence was predicted. These zero counts were assumed to be due to the lack of appropriate habitat at the site. However, the absence of fish in an area within its niche can also result from other processes not accounted for in this model, including predation, competition or fisheries removals. Although $32 \%$ zero counts is within an acceptable range for using the natural $\log +1$ data transformation, data sets with more zero counts should probably be treated differently (Shono 2008). In these cases, other methods such as applying a Tweedie distribution to avoid inherent problems with bias caused by the data transformation may be useful (Shono 2008). Still, treating the different sources of zero data differently is a distinct advantage when attempting to impart biological realism into a habitat model for marine fishes.

Application of this modeling method would be useful for describing essential fish habitat requirements for marine fishes, as well as for predicting changes in abundance and distribution of species. Using this type of modeling method, it is easy to compare the results to other regions, such as the comparisons here with the shortspine thornyhead distribution in the Aleutian Islands. It is also simple to predict the effects of changes in the variables on fish distribution. For example, the effects of a decrease in the shrimp prey base of shortspine thornyhead could easily be estimated for trawl survey stations in the Gulf of Alaska using this model. Because the model is based on ecological theory and environmental variables that are proxies for important processes determining survival and growth of fishes, the model should provide meaningful predictive capabilities and usefulness to researchers responsible for managing fish stocks.

Acknowledgements. Thank you to S. Kotwicki for his advice on resampling and modeling and J. Boldt for assisting with the kriging. This manuscript benefited greatly from reviews and discussions with M. Wilkins, S. Kotwicki, D. Somerton, S. Lowe and 3 anonymous reviewers.

\section{LITERATURE CITED}

Akaike H (1992) Information theory and an extension of the maximum likelihood principle. In: Kotz S, Johnson N (eds) Breakthroughs in statistics, Vol 1. Springer-Verlag, New York, NY, p 610-624

Barry SC, Welsh AH (2002) Generalized additive modeling and zero inflated count data. Ecol Modell 157:179-188

Britt LL, Martin MH (2001) Data report: 1999 Gulf of Alaska bottom trawl survey. NOAA Tech Memo NMFS-AFSC121. US Department of Commerce, Seattle, WA

Burnham KP, Anderson DR (2002) Model selection and multimodel inference: a practical information-theoretic approach, 2nd edn. Springer-Verlag, New York, NY

Else P, Haldorson L, Krieger K (2002) Shortspine thornyhead (Sebastolobus alascanus) abundance and habitat associations in the Gulf of Alaska. Fish Bull US 100:193-199

Freese JL (2001) Trawl-induced damage to sponges observed from a research submersible. Mar Fish Rev 63:7-13

Friedlander AM, Parrish JD (1998) Habitat characteristics affecting fish assemblages on a Hawaiian coral reef. J Exp Mar Biol Ecol 224:1-30

> Guisan A, Thuiller W (2005) Predicting species distribution: offering more than simple habitat models. Ecol Lett 8: 993-1009

Harvey CJ (2005) Effects of El Nino events on energy demand and egg production of rockfish (Scorpaenidae: Sebastes): a bioenergetics approach. Fish Bull US 103:71-83

Hilborn R, Mangel M (1997) The ecological detective: confronting models with data. Princeton University Press, Princeton, NJ

Hutchinson GE (1957) Concluding remarks. Cold Spring Harb Symp Quant Biol 22:415-427

> Iles TC, Beverton RJH (2000) The concentration hypothesis: the statistical evidence. ICES J Mar Sci 57:216-227

> Jacobson LD, Vetter RD (1996) Bathymetric demography and niche separation of thornyhead rockfish: Sebastolobus alascanus and Sebastolobus altivelis. Can J Fish Aquat Sci 53:600-609

> Ladd C, Hunt GL Jr, Mordy C, Salo S, Stabeno P (2005) Marine environment of the eastern and central Aleutian Islands. Fish Oceanogr 14:22-38

> Lauth RR, Ianelli J, Wakefield WW (2004a) Estimating the size selectivity and catching efficiency of a survey bottom trawl for thornyheads, Sebastolobus spp. using a towed video camera sled. Fish Res 70:27-37

> Lauth RR, Wakefield WW, Smith K (2004b) Estimating the density of thornyheads, Sebastolobus spp., using a towed video camera sled. Fish Res 70:39-48

> Logerwell EA, Aydin K, Barbeaux S, Brown E and others (2005) Geographic patterns in the demersal ichthyofauna of the Aleutian Islands. Fish Oceanogr 14:93-112

Love MS, Yoklavich M, Thorsteinson L (2002) The rockfishes of the northeast Pacific. University of California Press, Berkeley and Los Angeles, CA

Martin TG, Wintle BA, Rhodes JR, Kuhnert PM and others (2005) Zero tolerance ecology: improving ecological inference by modeling the source of zero observations. Ecol Lett 8:1235-1246

May RM (1973) Stability and complexity in model ecosystems. Princeton University Press, Princeton, NJ

$>$ Murawski SA, Finn JT (1988) Biological basis for mixed-species fisheries: species co-distribution in relation to environmental and biotic variables. Can J Fish Aquat Sci 45: 1720-1735

North Pacific Fishery Management Council (2007) Stock assessment and fishery evaluation report for the groundfish resources of the Gulf of Alaska, November 2007. North Pacific Fishery Management Council, Anchorage, AK

Pearcy WG, Stein DL, Hixon MA, Pikitch EK, Barss WH, Starr RM (1989) Submersible observations of deep-reef fishes of Heceta Bank, Oregon. Fish Bull US 87:955-965

Rooper CN (2008) An ecological analysis of rockfish (Sebastes spp.) assemblages in the north Pacific along broad-scale environmental gradients. Fish Bull US 171:1-11

Rooper CN, Boldt JL (2005) Distribution of juvenile Pacific 
ocean perch (Sebastes alutus) in the Aleutian Islands in relation to benthic habitat. Alaska Fish Res Bull 11: 102-112

Rooper CN, Zimmermann M, Spencer P (2005) Distribution of flathead sole (Hippoglossoides elassodon) by habitat in the eastern Bering Sea. Mar Ecol Prog Ser 290:251-262

Rooper CN, Boldt JL, Zimmermann M (2007) An assessment of juvenile Pacific ocean perch (Sebastes alutus) habitat use in a deepwater nursery. Estuar Coast Shelf Sci 75: $371-380$

Shono H (2008) Application of the Tweedie distribution to zero-catch data in CPUE analysis. Fish Res 93:154-162

Stauffer G (2004) NOAA protocols for groundfish bottom trawl surveys of the nation's fishery resources. NOAA Tech Memo NMFS-F/SPO-65. US Department of Commerce, Seattle, WA

Stein DL, Tissot BN, Hixon MA, Barss W (1992) Fish-habitat associations on a deep reef at the edge of the Oregon continental shelf. Fish Bull US 90:540-551

Stoner AW, Manderson JP, Pessutti JP (2001) Spatially explicit analysis of estuarine habitat for juvenile winter flounder: combining generalized additive models and geographic information systems. Mar Ecol Prog Ser 213:253-271

Strom SL, Olson MB, Macri EL, Mordy CW (2006) Cross-shelf gradients in phytoplankton community structure, nutrient utilization, and growth rate in the coastal Gulf of Alaska. Mar Ecol Prog Ser 328:75-92

Swartzman G, Huang C, Kaluzny S (1992) Spatial analysis of Bering Sea groundfish survey data using generalized additive models. Can J Fish Aquat Sci 49:1366-1378

Tolimieri N, Levin PS (2006) Assemblage structure of eastern Pacific groundfishes on the U. S. continental slope in rela-

Editorial responsibility: Konstantinos Stergiou, Thessaloniki, Greece tion to physical and environmental variables. Trans Am Fish Soc 135:317-332

Walsh SJ, Simpson M, Morgan MJ (2004) Continental shelf nurseries and recruitment variability in American plaice and yellowtail flounder on the Grand Bank: insights into stock resiliency. J Sea Res 51:271-286

Weinberg KL (1994) Rockfish assemblages of the middle shelf and upper slope off Oregon and Washington. Fish Bull US 92:620-632

Welsh AH, Cunningham RB, Donnelly CF, Lindenmayer DB (1996) Modelling the abundance of rare species: statistical models for counts with extra zeros. Ecol Modell 88: 297-308

Whitney FA, Crawford WR, Harrison PJ (2005) Physical processes that enhance nutrient transport and primary productivity in the coastal and open ocean of the subarctic NE Pacific. Deep-Sea Res II 52:681-706

Williams EH, Ralston S (2002) Distribution and co-occurrence of rockfishes (family: Sebastidae) over trawlable shelf and slope habitats of California and southern Oregon. Fish Bull US 100:836-855

Yang MS (2003) Food habits of the important groundfishes in the Aleutian Islands in 1994 and 1997. AFSC Processed Report 2003-07. US Department of Commerce, Seattle, WA

Yang MS, Dodd K, Hibpshman R, Whitehouse A (2006) Food habits of groundfishes in the Gulf of Alaska in 1999 and 2001. NOAA Tech Memo NMFS-AFSC-164. US Department of Commerce, Seattle, WA

Zenger HH Jr (2004) Data report: 2002 Aleutian Islands bottom trawl survey. NOAA Tech Memo NMFS-AFSC-143. US Department of Commerce, Seattle, WA

Submitted: August 13, 2008; Accepted: December 19, 2009 Proofs received from author(s): March 17, 2009 